\title{
A Stability Analysis for Magnetohydrodynamics Stagnation Point Flow with Zero Nanoparticles Flux Condition and Anisotropic Slip
}

\author{
Najiyah Safwa Khashi'ie ${ }^{1,2, *(1)}$, Norihan Md Arifin ${ }^{1,3}$, Roslinda Nazar ${ }^{4}$, \\ Ezad Hafidz Hafidzuddin ${ }^{5}$, Nadihah Wahi ${ }^{3}$ and Ioan Pop ${ }^{6}$ \\ 1 Institute for Mathematical Research, Universiti Putra Malaysia, Serdang 43400 UPM, Selangor, Malaysia; \\ norihana@upm.edu.my \\ 2 Fakulti Teknologi Kejuruteraan Mekanikal dan Pembuatan, Universiti Teknikal Malaysia Melaka, \\ Hang Tuah Jaya, Durian Tunggal 76100, Melaka, Malaysia \\ 3 Department of Mathematics, Faculty of Science, Universiti Putra Malaysia, Serdang 43400 UPM, Selangor, \\ Malaysia; nadihah@upm.edu.my \\ 4 School of Mathematical Sciences, Faculty of Science and Technology, Universiti Kebangsaan Malaysia, \\ Bangi 43600 UKM, Selangor, Malaysia; rmn@ukm.edu.my \\ 5 Centre of Foundation Studies for Agricultural Science, Universiti Putra Malaysia, Serdang 43400 UPM, \\ Selangor, Malaysia; ezadhafidz@upm.edu.my \\ 6 Department of Mathematics, Babeş-Bolyai University, R-400084 Cluj-Napoca, Romania; \\ popm.ioan@yahoo.co.uk \\ * Correspondence: najiyah@utem.edu.my
}

Received: 12 January 2019; Accepted: 19 February 2019; Published: 2 April 2019

\begin{abstract}
The numerical study of nanofluid stagnation point flow coupled with heat and mass transfer on a moving sheet with bi-directional slip velocities is emphasized. A magnetic field is considered normal to the moving sheet. Buongiorno's model is utilized to assimilate the mixed effects of thermophoresis and Brownian motion due to the nanoparticles. Zero nanoparticles' flux condition at the surface is employed, which indicates that the nanoparticles' fraction are passively controlled. This condition makes the model more practical for certain engineering applications. The continuity, momentum, energy and concentration equations are transformed into a set of nonlinear ordinary (similarity) differential equations. Using bvp4c code in MATLAB software, the similarity solutions are graphically demonstrated for considerable parameters such as thermophoresis, Brownian motion and slips on the velocity, nanoparticles volume fraction and temperature profiles. The rate of heat transfer is reduced with the intensification of the anisotropic slip (difference of two-directional slip velocities) and the thermophoresis parameter, while the opposite result is obtained for the mass transfer rate. The study also revealed the existence of non-unique solutions on all the profiles, but, surprisingly, dual solutions exist boundlessly for any positive value of the control parameters. A stability analysis is implemented to assert the reliability and acceptability of the first solution as the physical solution.
\end{abstract}

Keywords: nanofluid; stagnation sheet; three-dimensional flow; slip condition; stability analysis

\section{Introduction}

Nanofluids are a special class of fluids that have been the subject of developing research in the recent years. The dispersion of single nanoparticles like metals, oxides, carbon nanotubes or carbides in a fluid can create a modern class of fluids known as nanofluid. Water, oil and ethylene glycol are the common base fluid used in the formation of nanofluid. The invention of nanofluids that have good thermophysical properties can improve heat transfer performance for enormous 
futuristic applications such as in nuclear cooling systems, solar water heating, biomedical applications, lubrication, thermal storage, refrigeration, coolant in automobile radiator, and many others [1-13]. Choi et al. [14] initiated an experiment on nanotube-in-oil suspensions and measured that the thermal conductivity is inevitably greater than the theoretical predictions. An analytical model by Buongiorno [15] highlighted the importance of thermophoresis and Brownian motion that can induce a relative velocity between the nanoparticles and base fluid. Nield and Kuznetsov [16] implemented Buongiorno's model on the Cheng-Minkowycz problem for flow in a porous medium filled with nanofluid. A brief study of nanofluid and its thermal conductivity has also been examined by Buongiorno et al. [17]. Kuznetsov and Nield [18] revised their model [16] by introducing a new boundary condition that could manipulate the nanoparticles' volume fraction at the surface. Based on the report, it is assumed that the nanoparticles' volume fraction is passively controlled at the boundary which could make the new model more realistic and physically applicable as compared to the existing model. Muhammad et al. [19] also imposed coupled effects of convective heat and zero nanoparticles flux on conditions for Darcy-Forchheimer flow of Maxwell nanofluid. In addition, research works on the zero nanoparticles flux condition were also considered by Rehman et al. [20], Rahman et al. [21], Uddin et al. [22], ur Rahman et al. [23] and Jusoh et al. [24]. Furthermore, studies on the boundary layer problem utilizing Buongiorno's model of nanofluid were also conducted by these researchers [25-31].

Magnetohydrodynamics (MHD), also acknowledged as hydromagnetics and magneto-fluid dynamics, is the study on the behaviour of electrically conducting fluids including liquid metals, plasmas, electrolytes and salt water. The magnetic fields can generate currents or Lorentz force in a moving fluid, which give resistance to the fluid flow and, simultaneously, changes the magnetic field. Magnetohydrodynamics are effectively applied in many devices such as generators, power pumps, heat exchangers and electrostatic filters. The imposition of the magnetic field is also practical in maintaining the boundary layer flow. Rashidi et al. [32] introduced a new analytical method (DTM-Padé) to solve the boundary-layer equations of an MHD micropolar fluid near an isothermal-stretching sheet and concluded that the DTM-Padé is applicable for solving magnetohydrodynamic (MHD) boundary-layer equations. Rashidi et al. [33] concluded that the magnetic nanofluid flow over a porous rotating disk was beneficial in rotating MHD energy generators for new space systems. Sheikholeslami et al. [34] investigated the problem of an eccentric semi-annulus saturated with nanofluid under the influence of a magnetic field. Hayat et al. [35] studied the combined effects of magnetic field, velocity slip and nonlinear thermal radiation on the three-dimensional nanofluid flow. Kandasamy et al. [36] considered the convective condition for an MHD mixed convection flow in a nanofluid while Bhatti et al. [37] analyzed the MHD Wlliamson nanofluid over a porous shrinking sheet. An external magnetic field was imposed, while the induced magnetic field was neglected due to the negligible magnetic Reynolds number. Bhatti et al. [38] examined the coupled effects of MHD and partial slip on the blood flow using a Ree-Eyring fluid model. Makulati et al. [39] utilized the Tiwari and Das model of water-alumina nanofluid to study the impact of a magnetic field in inclined C-shaped enclosures. Hussain et al. [40] found that an upsurge of magnetic field, Hall current, rotation and chemical reaction had an impact on the fluid flow over an accelerated moving plate.

Stagnation point flows are fluid flows that approach the surface of a solid object and then separate into different streams. Stagnation region which meets the maximum pressure, heat transfer and mass deposition are essential in the industrial and technological field. Early classical works on stagnation flow that excluded the slip velocity effect were examined by Hiemenz [41] for the two-dimensional problem, Homann [42] for the axisymmetric case and Howarth [43] for the flow near the stagnation region. According to Wang [44], anisotropy is reflected in the difference of bi-directional (direction) slip velocities. Previously, Wang had considered the problem of two-dimensional stagnation flow with symmetric axes on dissimilar surfaces; stationary plate with isotropic slip [45] and moving plate [46], respectively. The results indicated that the enhancement of slip parameter will change the surface resistance and velocity profile. Hussain et al. [47] studied the slip flow and heat transfer of nanofluids embedded in a Darcy-type porous medium. From the analysis, the increment in the 
permeability of the porous medium and the velocity slip parameter increased the heat transfer rate, whereas it decreased the momentum and thermal boundary layer thicknesses. Khan et al. [48] also pointed up the significance of wall velocity slip for a reliable design and operation of microfluidic devicesmade of hydrophobic devices. The emerging numbers of industrial and technological applications make the study of anisotropic slip that relies upon the flow direction, which is influential for these types of surfaces: hydrophobic [49-54] and porous [55,56]. Rashad [57] investigated the coupled effects of anisotropic slip and convective condition in an unsteady nanofluid saturated with porous medium. Hafidzuddin et al. [58] discussed the anisotropic slip on stagnation flow due to a permeable moving surface, which resulted in dual solutions attained with the presence of a suction parameter. Numerous studies involving three-dimensional stagnation nanofluid flow towards a moving anisotropic slip surface are conducted by Raees et al. [59], Uddin et al. [60] and Balushi et al. [61]. Very recently, Sadiq [62] concluded that the intensity of magnetic field and velocity slip cause an increase in the nanofluid velocity while the boundary layer thickness decreases near the stagnation point region.

Motivated by the literature mentioned earlier, the current work accentuates the anisotropic slip effect on the numerical solution of stagnation point flow with nanoparticles due to a moving surface. Buongiorno's model of nanofluid with an assumption of zero normal flux condition at the wall is implemented. A set of transformations is applied on the governing model to simplify them into nonlinear ordinary differential equations (ODEs). The bvp4c function in MATLAB software (R2017b, MathWorks, Natick, MA, USA) is utilized to perform the numerical computations. The numerical results are demonstrated in the graph forms of velocity, nanoparticles concentration and temperature including the skin friction coefficient, heat and mass transfer rate within the specific range of related parameters. The authors also concern about the emergence of non-unique solutions and the way of stability analysis is conducted to prove the physical solution. The pioneer works on formulation of stability analysis were conducted by Merkin [63], Weidman et al. [64], Harris et al. [65] and Roşca and Pop [66]. A brief of explanation on stability analysis was also discussed by the following literature [67-74]. To the best of the authors' knowledge, the results are new and have not been published.

\section{Mathematical Formulation}

Consider a steady, three-dimensional stagnation point flow of a nanofluid towards a moving sheet with the presence of anisotropic slip as illustrated in Figure 1. $U_{x}$ and $V_{y}$ are the moving plate velocities along the $x$ - and $y$-directions while the $z$-axis is the axis of stagnation flow. A magnetic field of consistent strength $B_{0}$ is applied normal to the plate. The surface is kept with fixed temperature, $T_{w}$ while variable nanoparticles fraction, $D_{B} \frac{\partial C}{\partial z}+\frac{D_{T}}{T_{\infty}} \frac{\partial T}{\partial z}$ is adapted at $z=0$. This condition is applied to achieve practically applicable results [18-24]. The ambient nanofluid concentration and temperature are denoted as $C_{\infty}$ and $T_{\infty}$.

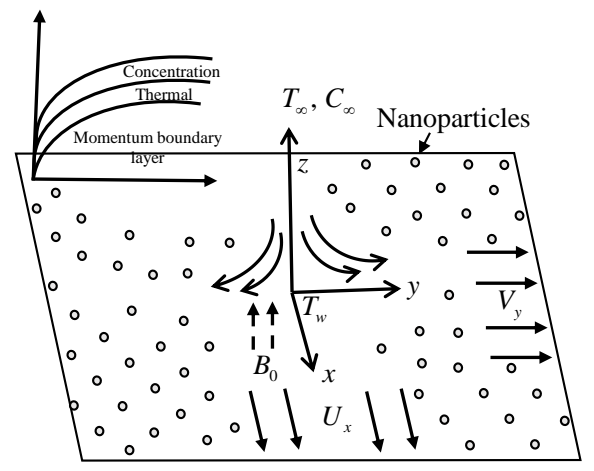

Figure 1. The coordinate system of the physical model. 
The following assumptions for the physical model are also contemplated in the present work:

- The nanoparticles and the base fluid is maintained in a thermal equilibrium state.

- The Buongiorno's model of nanofluid is used to mix the combined effects of Brownian motion and thermophoresis.

- The insignificant value of the magnetic Reynolds number is assumed so that the induced magnetic field is zero.

- The Hall current effect is also omitted due to the absence of any externally applied electric field.

Under all these assumptions, the flow equations are:

$$
\begin{gathered}
\frac{\partial u}{\partial x}+\frac{\partial v}{\partial y}+\frac{\partial w}{\partial z}=0 \\
u \frac{\partial u}{\partial x}+v \frac{\partial u}{\partial y}+w \frac{\partial u}{\partial z}=U_{e}(x) \frac{d U_{e}(x)}{d x}+v \nabla^{2} u-\frac{\sigma_{M} B_{0}^{2}}{\rho}\left(u-U_{e}(x)\right) \\
u \frac{\partial v}{\partial x}+v \frac{\partial v}{\partial y}+w \frac{\partial v}{\partial z}=V_{e}(y) \frac{d V_{e}(y)}{d y}+v \nabla^{2} v-\frac{\sigma_{M} B_{0}^{2}}{\rho}\left(v-V_{e}(y)\right) \\
u \frac{\partial w}{\partial x}+v \frac{\partial w}{\partial y}+w \frac{\partial w}{\partial z}=v \nabla^{2} w \\
u \frac{\partial T}{\partial x}+v \frac{\partial T}{\partial y}+w \frac{\partial T}{\partial z}=\alpha \nabla^{2} T+\tau_{1} D_{B}\left[\frac{\partial T}{\partial x} \frac{\partial C}{\partial x}+\frac{\partial T}{\partial y} \frac{\partial C}{\partial y}+\frac{\partial T}{\partial z} \frac{\partial C}{\partial z}\right]+\tau_{1} \frac{D_{T}}{T_{\infty}}\left[\left(\frac{\partial T}{\partial x}\right)^{2}+\left(\frac{\partial T}{\partial y}\right)^{2}+\left(\frac{\partial T}{\partial z}\right)^{2}\right] \\
u \frac{\partial C}{\partial x}+v \frac{\partial C}{\partial y}+w \frac{\partial C}{\partial z}=D_{B} \nabla^{2} C+\frac{D_{T}}{T_{\infty}} \nabla^{2} T
\end{gathered}
$$

subject to the initial and boundary conditions

$$
\begin{aligned}
& u(x, y, 0)=\lambda U_{x}+\left.\mu S_{1} \frac{\partial u}{\partial z}\right|_{(x, y, 0)}, v(x, y, 0)=\lambda V_{y}+\left.\mu S_{2} \frac{\partial v}{\partial z}\right|_{(x, y, 0)}, w(x, y, 0)=0, \\
& T(x, y, 0)=T_{w},\left[D_{B} \frac{\partial C}{\partial z}+\frac{D_{T}}{T_{\infty}} \frac{\partial T}{\partial z}\right]_{(x, y, 0)}=0, \\
& \left.\begin{array}{l}
u(x, y, z) \rightarrow U_{e}(x)=b x, \quad v(x, y, z) \rightarrow V_{e}(y)=b y, \quad T(x, y, z) \rightarrow T_{\infty}, \\
C(x, y, z) \rightarrow C_{\infty} \text { as } z \rightarrow \infty,
\end{array}\right\},
\end{aligned}
$$

where $(u, v, w)$ are the respective velocities in $(x, y, z)$ directions, $T$ is the fluid temperature, $C$ is the nanoparticles volume fraction, $v$ is the kinematic viscosity, $\mu$ is the dynamic viscosity, $\sigma_{M}$ is the electrical conductivity of the fluid, $\rho$ is the fluid density, $\tau_{1}$ is the ratio of heat capacity of the nanoparticles to the base fluid, $\alpha$ is the thermal diffusivity, $D_{B}$ is the Brownian diffusion coefficient, $D_{T}$ is the thermophoretic diffusion coefficient, $S_{1}$ is the slip coefficient in $x$-direction, $S_{2}$ is the slip coefficient in $y$-direction, $b$ is the strength of the stagnation flow, and $\lambda$ is the moving parameter such that $\lambda>0$ and $\lambda<0$ refer to the moving plate, which is out and towards the origin, respectively [58,75].

The following similarity transformations which satisfy Equation (1) are employed to convert the PDEs in Equations (2)-(6) aligned with the conditions (see Equations (7) and (8)) into a set of ODEs:

$$
\left.\begin{array}{c}
u=b x f^{\prime}(\eta)+U_{x} h(\eta), \quad v=b y g^{\prime}(\eta)+V_{y} k(\eta), \quad w=-\sqrt{b v}[f(\eta)+g(\eta)], \\
T=\left(T_{w}-T_{\infty}\right) \theta(\eta)+T_{\infty}, \quad C=\left(C_{w}-C_{\infty}\right) \phi(\eta)+C_{\infty}, \quad \eta=\sqrt{\frac{b}{v}} z,
\end{array}\right\}
$$

where $\eta$ is the similarity variable. Hence, the transformed nonlinear ODEs in conjunction with the conditions are:

$$
f^{\prime \prime \prime}=\left(f^{\prime}\right)^{2}-(f+g) f^{\prime \prime}+M\left(f^{\prime}-1\right)-1,
$$




$$
\begin{gathered}
g^{\prime \prime \prime}=\left(g^{\prime}\right)^{2}-(f+g) g^{\prime \prime}+M\left(g^{\prime}-1\right)-1, \\
h^{\prime \prime}=h f^{\prime}-(f+g) h^{\prime}+M h, \\
k^{\prime \prime}=k g^{\prime}-(f+g) k^{\prime}+M k, \\
\theta^{\prime \prime}=-\operatorname{Pr}\left[(f+g) \theta^{\prime}+N b \theta^{\prime} \phi^{\prime}+N t\left(\theta^{\prime}\right)^{2}\right], \\
\phi^{\prime \prime}=-L e \operatorname{Pr}(f+g) \phi^{\prime}-\frac{N t}{N b} \theta^{\prime \prime}, \\
\begin{array}{l}
f(0)=g(0)=0, \gamma_{1} f^{\prime \prime}(0)=f^{\prime}(0), \gamma_{2} g^{\prime \prime}(0)=g^{\prime}(0), \lambda+\gamma_{1} h^{\prime}(0)=h(0), \lambda+\gamma_{2} k^{\prime}(0)=k(0), \\
\theta(0)=1, \quad N b \phi^{\prime}(0)+N t \theta^{\prime}(0)=0,
\end{array} \\
\left.f^{\prime}(\eta) \rightarrow 1, \quad g^{\prime}(\eta) \rightarrow 1, \quad h(\eta) \rightarrow 0, \quad k(\eta) \rightarrow 0, \quad \theta(\eta) \rightarrow 0, \quad \phi(\eta) \rightarrow 0 \quad \text { as } \quad \eta \rightarrow \infty,\right\}
\end{gathered}
$$

where primes denote differentiation with respect to similarity variable $\eta, M=\frac{\sigma_{M} B_{0}{ }^{2}}{\rho b}$ is the magnetic field parameter, $N t=\frac{\tau_{1} D_{T}\left(T_{w}-T_{\infty}\right)}{v T_{\infty}}$ is the thermophoresis parameter, $N b=\frac{\tau_{1} D_{B}\left(C_{w}-C_{\infty}\right)}{v}$ is the Brownian motion parameter, $\operatorname{Pr}=\frac{v}{\alpha}$ is the Prandtl number, $L e=\frac{\alpha}{D_{B}}$ is the Lewis number, $\gamma_{1}=\mu S_{1} \sqrt{\frac{b}{v}}$ and $\gamma_{2}=\mu S_{2} \sqrt{\frac{b}{v}}$ are the slip parameters in the bi-directional $x$ - and $y$-axis, proportionately. The physical interests in the study are the dimensionless skin friction coefficient, local Nusselt number (heat transfer rate) and local Sherwood number (mass transfer rate) which is denoted by

$$
C_{f} R e_{x}^{1 / 2}=f^{\prime \prime}(0), \quad \frac{N u_{x}}{R e_{x}^{1 / 2}}=-\theta^{\prime}(0), \quad \frac{S h_{x}}{R e_{x}^{1 / 2}}=-\phi^{\prime}(0),
$$

accordingly.

\section{Stability Analysis}

The implementation of stability analysis is essential to affirm mathematically the stability and reliability of the dual solutions. The first non-unique solution which is asymptotically satisfying the boundary conditions will be denoted as the first or upper branch solution. For stability purposes, a time-dependent problem needs to be considered based on study in previous literature [67-73]. The unsteady form of Equations (2)-(6) is

$$
\begin{gathered}
\frac{\partial u}{\partial t}+u \frac{\partial u}{\partial x}+v \frac{\partial u}{\partial y}+w \frac{\partial u}{\partial z}=U_{e}(x) \frac{d U_{e}(x)}{d x}+v \nabla^{2} u-\frac{\sigma_{M} B_{0}^{2}}{\rho}\left(u-U_{e}(x)\right) \\
\frac{\partial v}{\partial t}+u \frac{\partial v}{\partial x}+v \frac{\partial v}{\partial y}+w \frac{\partial v}{\partial z}=V_{e}(y) \frac{d V_{e}(y)}{d y}+v \nabla^{2} v-\frac{\sigma_{M} B_{0}^{2}}{\rho}\left(v-V_{e}(y)\right) \\
\frac{\partial w}{\partial t}+u \frac{\partial w}{\partial x}+v \frac{\partial w}{\partial y}+w \frac{\partial w}{\partial z}=v \nabla^{2} w \\
\frac{\partial T}{\partial t}+u \frac{\partial T}{\partial x}+v \frac{\partial T}{\partial y}+w \frac{\partial T}{\partial z}=\alpha \nabla^{2} T+\tau_{1} D_{B}\left[\frac{\partial T}{\partial x} \frac{\partial C}{\partial x}+\frac{\partial T}{\partial y} \frac{\partial C}{\partial y}+\frac{\partial T}{\partial z} \frac{\partial C}{\partial z}\right] \\
+\tau_{1} \frac{D_{T}}{T_{\infty}}\left[\left(\frac{\partial T}{\partial x}\right)^{2}+\left(\frac{\partial T}{\partial y}\right)^{2}+\left(\frac{\partial T}{\partial z}\right)^{2}\right], \\
\frac{\partial C}{\partial t}+u \frac{\partial C}{\partial x}+v \frac{\partial C}{\partial y}+w \frac{\partial C}{\partial z}=D_{B} \nabla^{2} C+\frac{D_{T}}{T_{\infty}} \nabla^{2} T
\end{gathered}
$$


New transformations are applied to the unsteady problem (see Equations (19)-(23)) where $\tau$ is the non-dimensional time variable:

$$
\left.\begin{array}{c}
u=b x \frac{\partial f(\eta, \tau)}{\partial \eta}+U_{x} h(\eta, \tau), \quad v=b y \frac{\partial g(\eta, \tau)}{\partial \eta}+V_{y} k(\eta, \tau), \quad w=-\sqrt{b v}[f(\eta, \tau)+g(\eta, \tau)], \\
T=\left(T_{w}-T_{\infty}\right) \theta(\eta, \tau)+T_{\infty}, \quad C=\left(C_{w}-C_{\infty}\right) \phi(\eta, \tau)+C_{\infty}, \quad \eta=\sqrt{\frac{b}{v}} z, \quad \tau=b t .
\end{array}\right\}
$$

Using Equation (24), the following equations can be attained:

$$
\begin{gathered}
\frac{\partial^{3} f}{\partial \eta^{3}}+(f+g) \frac{\partial^{2} f}{\partial \eta^{2}}-\left(\frac{\partial f}{\partial \eta}\right)^{2}-M\left(\frac{\partial f}{\partial \eta}-1\right)+1-\frac{\partial^{2} f}{\partial \eta \partial \tau}=0 \\
\frac{\partial^{3} g}{\partial \eta^{3}}+(f+g) \frac{\partial^{2} g}{\partial \eta^{2}}-\left(\frac{\partial g}{\partial \eta}\right)^{2}-M\left(\frac{\partial g}{\partial \eta}-1\right)+1-\frac{\partial^{2} g}{\partial \eta \partial \tau}=0 \\
\frac{\partial^{2} h}{\partial \eta^{2}}+(f+g) \frac{\partial h}{\partial \eta}-h \frac{\partial f}{\partial \eta}-M h-\frac{\partial h}{\partial \tau}=0 \\
\frac{\partial^{2} k}{\partial \eta^{2}}+(f+g) \frac{\partial k}{\partial \eta}-k \frac{\partial g}{\partial \eta}-M k-\frac{\partial k}{\partial \tau}=0 \\
\frac{\partial^{2} \theta}{\partial \eta^{2}}+\operatorname{Pr}\left[(f+g) \frac{\partial \theta}{\partial \eta}+N b \frac{\partial \theta}{\partial \eta} \frac{\partial \phi}{\partial \eta}+N t\left(\frac{\partial \theta}{\partial \eta}\right)^{2}-\frac{\partial \theta}{\partial \tau}\right]=0 \\
\frac{\partial^{2} \phi}{\partial \eta^{2}}+L e \operatorname{Pr}\left[(f+g) \frac{\partial \phi}{\partial \eta}-\frac{\partial \phi}{\partial \tau}\right]+\frac{N t}{N b} \frac{\partial^{2} \theta}{\partial \eta^{2}}=0
\end{gathered}
$$

with the transformed conditions

$$
\begin{aligned}
& \left.\begin{array}{l}
f(0, \tau)=g(0, \tau)=0, \quad\left[\gamma_{1} \frac{\partial^{2} f}{\partial \eta^{2}}-\frac{\partial f}{\partial \eta}\right]_{(0, \tau)}=0, \quad\left[\gamma_{2} \frac{\partial^{2} g}{\partial \eta^{2}}-\frac{\partial g}{\partial \eta}\right]_{(0, \tau)}=0, \\
\lambda+\left.\gamma_{1} \frac{\partial h}{\partial \eta}\right|_{(0, \tau)}=h(0, \tau), \quad \lambda+\left.\gamma_{2} \frac{\partial k}{\partial \eta}\right|_{(0, \tau)}=k(0, \tau), \quad \theta(0, \tau)=1, \quad\left[N b \frac{\partial \phi}{\partial \eta}+N t \frac{\partial \theta}{\partial \eta}\right]_{(0, \tau)}=0,
\end{array}\right\} \\
& \left.\left.\frac{\partial f}{\partial \eta}\right|_{(\eta, \tau)} \rightarrow 1,\left.\frac{\partial g}{\partial \eta}\right|_{(\eta, \tau)} \rightarrow 1, h(\eta, \tau) \rightarrow 0, k(\eta, \tau) \rightarrow 0, \theta(\eta, \tau) \rightarrow 0, \phi(\eta, \tau) \rightarrow 0 \text { as } \eta \rightarrow \infty .\right\}
\end{aligned}
$$

For the stability process, steady flow solutions $f(\eta)=f_{0}(\eta), g(\eta)=g_{0}(\eta), h(\eta)=h_{0}(\eta)$, $k(\eta)=k_{0}(\eta), \theta(\eta)=\theta_{0}(\eta)$ and $\phi(\eta)=\phi_{0}(\eta)$ which have satisfied Equations (10)-(17) are examined by the following expressions:

$$
\left.\begin{array}{l}
f(\eta, \tau)=f_{0}(\eta)+e^{-\sigma \tau} F(\eta) \\
g(\eta, \tau)=g_{0}(\eta)+e^{-\sigma \tau} G(\eta) \\
h(\eta, \tau)=h_{0}(\eta)+e^{-\sigma \tau} H(\eta) \\
k(\eta, \tau)=k_{0}(\eta)+e^{-\sigma \tau} K(\eta) \\
\theta(\eta, \tau)=\theta_{0}(\eta)+e^{-\sigma \tau} P(\eta) \\
\phi(\eta, \tau)=\phi_{0}(\eta)+e^{-\sigma \tau} R(\eta)
\end{array}\right\},
$$

where $\sigma$ is an eigenvalue, $F(\eta), G(\eta), H(\eta), K(\eta), P(\eta)$ and $R(\eta)$ are small relative to $f_{0}(\eta), g_{0}(\eta)$, $h_{0}(\eta), k_{0}(\eta), \theta_{0}(\eta)$ and $\phi_{0}(\eta)$, correspondingly [66]. The linearized eigenvalue problem will be attained by replacing Equation (33) into Equations (25)-(32):

$$
\begin{aligned}
& F^{\prime \prime \prime}+\left(f_{0}+g_{0}\right) F^{\prime \prime}+(F+G) f_{0}^{\prime \prime}-\left(2 f_{0}^{\prime}-\sigma+M\right) F^{\prime}=0, \\
& G^{\prime \prime \prime}+\left(f_{0}+g_{0}\right) G^{\prime \prime}+(F+G) g_{0}^{\prime \prime}-\left(2 g_{0}^{\prime}-\sigma+M\right) G^{\prime}=0,
\end{aligned}
$$




$$
\begin{gathered}
H^{\prime \prime}+\left(f_{0}+g_{0}\right) H^{\prime}+(F+G) h_{0}^{\prime}-h_{0} F^{\prime}-\left(f_{0}^{\prime}-\sigma+M\right) H=0, \\
K^{\prime \prime}+\left(f_{0}+g_{0}\right) K^{\prime}+(F+G) k_{0}^{\prime}-k_{0} G^{\prime}-\left(g_{0}^{\prime}-\sigma+M\right) K=0, \\
P^{\prime \prime}+\operatorname{Pr}\left[\left(f_{0}+g_{0}\right) P^{\prime}+(F+G) \theta_{0}^{\prime}+N b\left(\phi_{0}^{\prime} P^{\prime}+\theta_{0}^{\prime} R^{\prime}\right)+N t\left(2 \theta_{0}^{\prime} P^{\prime}\right)+\sigma P\right]=0, \\
R^{\prime \prime}+L e \operatorname{Pr}\left[\left(f_{0}+g_{0}\right) R^{\prime}+(F+G) \phi_{0}^{\prime}+\sigma R\right]+\frac{N t}{N b} P^{\prime \prime}=0,
\end{gathered}
$$

along with the conditions

$$
\left.\begin{array}{c}
F(0)=G(0)=0, \quad \gamma_{1} F^{\prime \prime}(0)=F^{\prime}(0), \quad \gamma_{2} G^{\prime \prime}(0)=G^{\prime}(0), \\
\gamma_{1} H^{\prime}(0)=H(0), \quad \gamma_{2} K^{\prime}(0)=K(0), \quad P(0)=0, \quad N b R^{\prime}(0)+N t P^{\prime}(0)=0
\end{array}\right\},
$$

The stability of the solutions $f_{0}(\eta), g_{0}(\eta), h_{0}(\eta), k_{0}(\eta), \theta_{0}(\eta)$ and $\phi_{0}(\eta)$ depends on the smallest eigenvalue, $\sigma_{1}$ by solving the governing linearized eigenvalue model in Equations (34)-(41). Relaxation of a boundary condition is necessary to attain a possible range of eigenvalues [65]. Hence, in the present paper, the boundary condition $F^{\prime}(\eta) \rightarrow 0$ as $\eta \rightarrow \infty$ (see Equation (41)) is relaxed and replaced with the normalizing boundary condition $F^{\prime \prime}(0)=1$.

\section{Results and Discussion}

The similarity solutions for the transformed ODEs in Equations (10)-(15) aligned with the conditions (see Equations (16) and (17)) are found with the aid of bvp4c function in MATLAB software. The bvp4c function implements a finite difference scheme known as 3-stage Lobatto IIIa [74,76-78]. There are four separate codes in bvp4c function; code a for solving steady flow equations, code $b$ for continuation of code a, code $c$ and d for stability analysis of dual solutions. In the bvp4c code a, $\eta_{\infty}=10$ is used for the numerical calculations, but it is found that $\eta_{\infty}=5$ is sufficient enough to fulfill the boundary conditions based on all the profiles demonstrated in the present study. For the method validation, few values in the case of Newtonian fluid with the absence of magnetic parameter and heat transfer have been compared to the results by Wang [44] and Balushi et al. [61]. The present numerical values are in positive agreement with others as tabulated in Table 1.

Table 1. A comparison data with previous published results for $\lambda=1, \gamma_{1}=5$ and various $\gamma_{2}$.

\begin{tabular}{ccccccc}
\hline & \multicolumn{2}{c}{ Present } & \multicolumn{2}{c}{ Wang [44] } & \multicolumn{2}{c}{ Balushi et al. [61] } \\
& $\gamma_{2}=\mathbf{5}$ & $\gamma_{2}=\mathbf{2 . 5}$ & $\gamma_{2}=\mathbf{5}$ & $\gamma_{2}=\mathbf{2 . 5}$ & $\gamma_{2}=\mathbf{5}$ & $\gamma_{2}=\mathbf{2 . 5}$ \\
\hline$f^{\prime}(0)$ & 0.896418 & 0.895885 & 0.8964 & 0.8959 & 0.896418 & 0.895885 \\
$g^{\prime}(0)$ & 0.896418 & 0.809985 & 0.8964 & 0.8100 & 0.896418 & 0.809985 \\
$h(0)$ & 0.122554 & 0.123428 & 0.123 & 0.123 & 0.122554 & 0.123428 \\
$k(0)$ & 0.122554 & 0.221884 & 0.123 & 0.222 & 0.122554 & 0.221884 \\
\hline
\end{tabular}

Figures 2-17 exhibit that dual solutions are possible in the present study. The first and second solutions are depicted by the straight and dashed lines, respectively. Generally, the solution which converges first is assumed as the first or physical solution, and in this case, the stability analysis as discussed in the previous section will affirm which solution is physically realizable. Figures 2-7 display the nanofluid velocities on $x$ - and $y$-directions, temperature and concentration profiles in limiting numbers of $\gamma_{2}$ when $L e=\operatorname{Pr}=1, N b=N t=0.2, M=0.5, \lambda=-1,1$ and $\gamma_{1}=5$. Both of the velocities as revealed in Figures 2 and 3 increase because the shear stress decrease with the enlargement of the slip parameter and this is supported by the result in Figure 11. Figures 4 and 5 demonstrate the slip velocity profiles $h(\eta)$ and $k(\eta)$ in both directions, respectively. There are opposite and symmetrically 
effect for both profiles at $\lambda= \pm 1$. The changes in $\lambda$ only influence the slip velocity profiles since the moving parameter only remains in the initial condition at $h(0)$ and $k(0)$ (see Equation (16)). Boundary layer thickness for both solutions diminishes with an increment of $\gamma_{2}$ as manifested in Figures 4 and 5 .

The nanofluid temperature as illustrated in Figure 6 declines with the expanding values of $\gamma_{2}$ while the opposite result is obtained for the nanoparticles' volume fraction profile in Figure 7. Meanwhile, Figures 8-10 present the influence of the $\mathrm{Nb}$ and $\mathrm{Nt}$ on both nanoparticles volume fraction (concentration) and temperature profiles. The nanofluid concentration diminishes as $\mathrm{Nb}$ increases while expands as $\mathrm{Nt}$ increases and these outcomes are in conjunction with the previous results by Balushi et al. [61]. An inflation of $N t$ seems to boost the thermal boundary layer thickness and temperature, whereas the presence of $\mathrm{Nb}$ give zero impact on the nanofluid temperature. The appearance of the nanoparticles in the base fluid will generate thermophoresis parameter. As $N t$ increases, the higher thermal conductivity in nanofluid will enhance both temperature and concentration.

Variations of $g^{\prime \prime}(0), k^{\prime}(0),-\theta^{\prime}(0)$ and $-\phi^{\prime}(0)$ against the slip parameter, $\gamma_{1}$ for selected values of $\gamma_{2}, N b$ and $N t$ are visualized in Figures 11-17, respectively. Unlike the other studies which conduct stability analysis for non-unique solutions, no critical value or turning point is found in this analysis. Critical value is defined as a value that separates the first (physical) and second solutions. Both upper and lower branches existing boundlessly for each value of $\gamma_{1}$ and for the graph visualization, $0 \leq \gamma_{1} \leq 30$ have been selected. There is no significant effect of $\gamma_{2}$ on $f^{\prime \prime}(0)$ and $h^{\prime}(0)$, hence the graph is not highlighted. This is supported by the velocity and slip velocity profile that have been shown previously in Figures 2 and 4 . Variations of $-\theta^{\prime}(0)$ and $-\phi^{\prime}(0)$ as can be seen in Figures 13 and 14 only show minimal changes as $\gamma_{2}$ increase but since the value of $N b$ and $N t$ is same, $-\theta^{\prime}(0)=-\left(-\phi^{\prime}(0)\right)$ for all values of $\gamma_{1}$ and $\gamma_{2}$. An increasing values of the Brownian motion parameter $\mathrm{Nb}$ escalate the mass transfer rate whereas the thermophoresis parameter $N t$ reduces both heat and mass transfer rate as displayed in Figures 15-17.

Since dual solutions are obtained in the study, a stability analysis has been conducted by solving Equations (34)-(39) with the conditions (see Equations (40) and (41)) using Matlab bvp4c code c and d. Generally, negative $\sigma_{1}$ indicates an initial upsurge of disturbances, which signifies that the flow is unstable while there are opposite flow characteristics for positive $\sigma_{1}$. The smallest eigenvalue, $\sigma_{1}$ for some values of $\gamma_{1}$, is tabulated in Table 2. It shows that the first and second solutions have positive and negative eigenvalues, respectively, which validate the stability and reliability of the first solution.

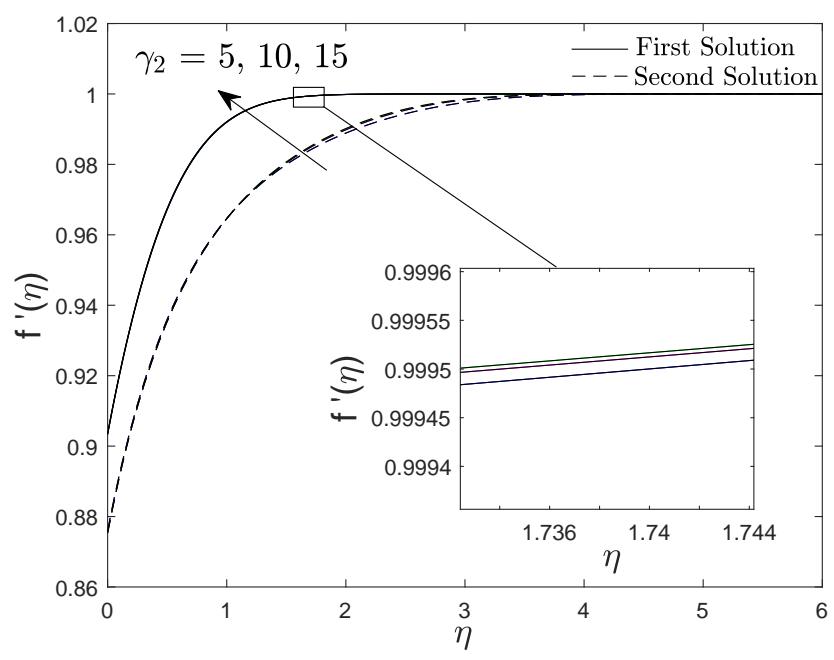

Figure 2. Nanofluid velocity along the $x$-direction for diverse values of $\gamma_{2}$ with $\lambda=-1,1$. 


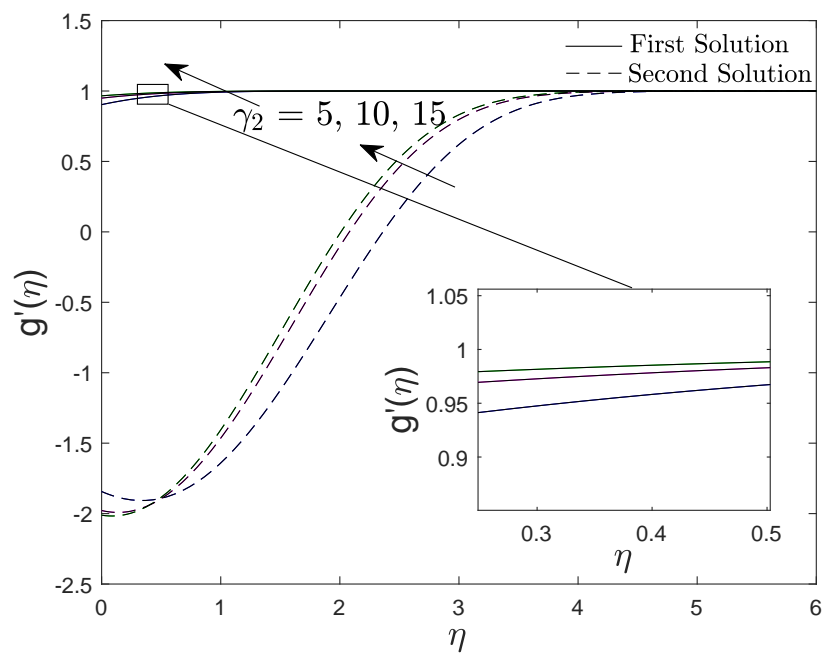

Figure 3. Nanofluid velocity along the $y$-direction for diverse values of $\gamma_{2}$ with $\lambda=-1,1$.

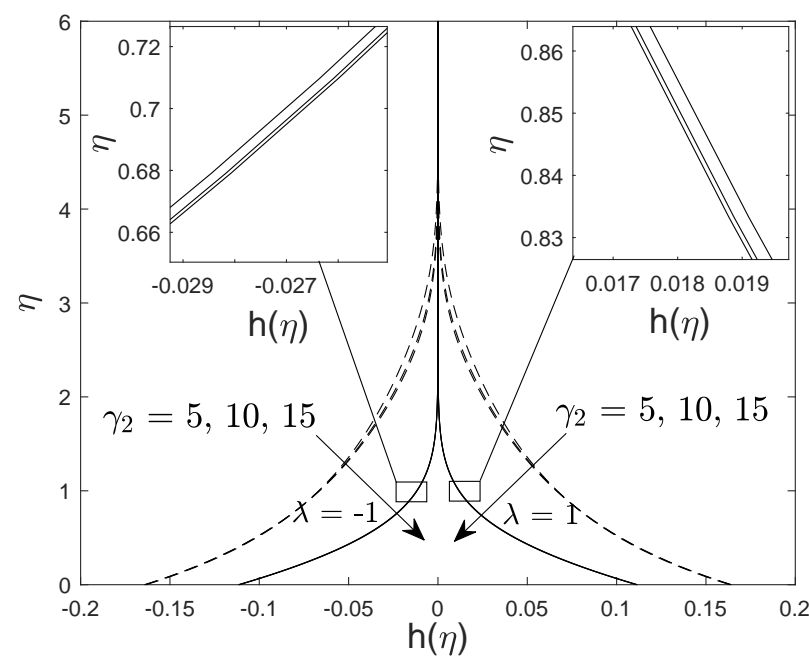

Figure 4. Slip velocity along the $x$-direction for diverse values of $\gamma_{2}$ with $\lambda=-1,1$.

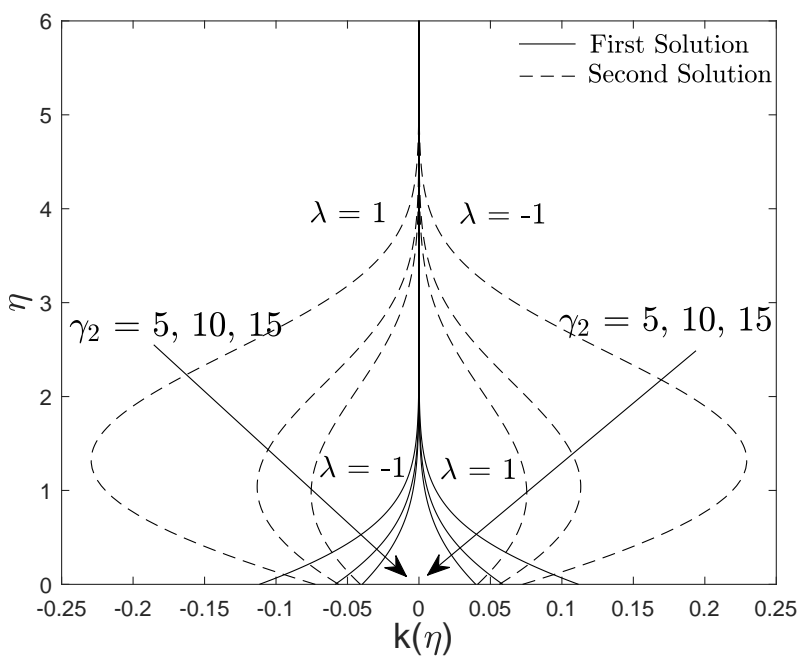

Figure 5. Slip velocity along the $y$-direction for diverse values of $\gamma_{2}$ with $\lambda=-1,1$. 


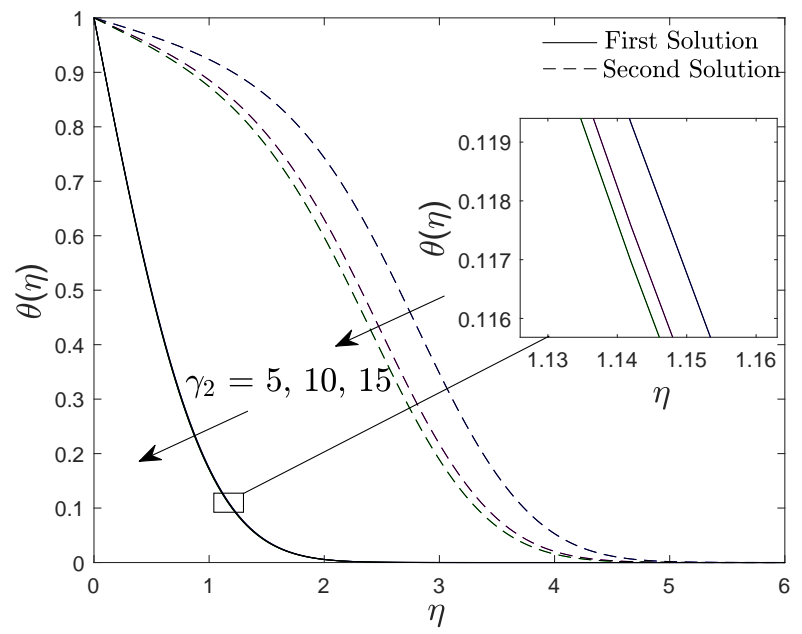

Figure 6. Nanofluid temperature in a limiting range of $\gamma_{2}$ with $\lambda=-1,1$.

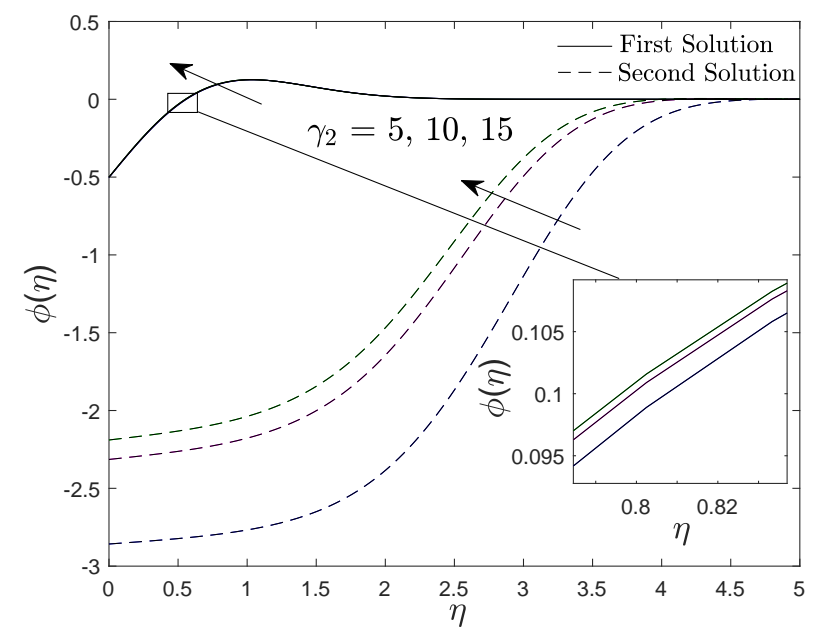

Figure 7. Nanoparticles volume fraction profile in a limiting range of $\gamma_{2}$ with $\lambda=-1,1$.

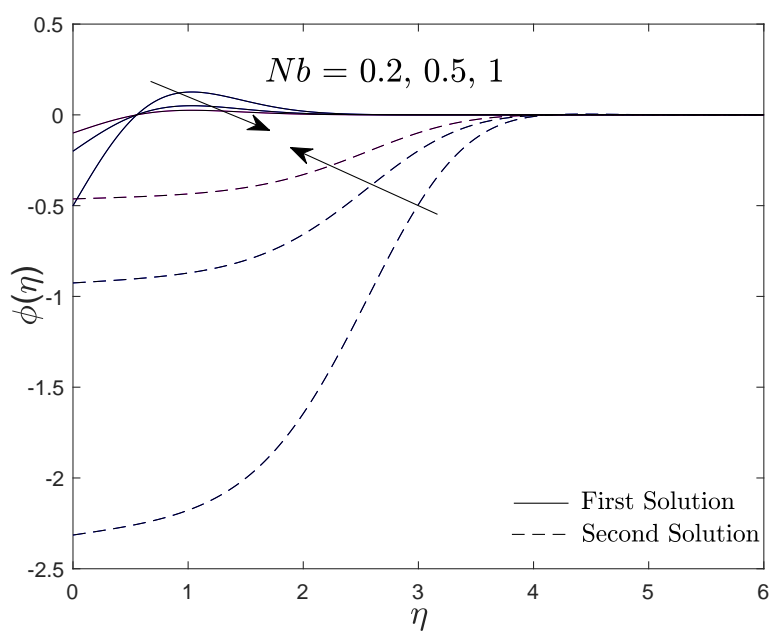

Figure 8. Nanoparticles' volume fraction profile in limiting range of $N b$ when $L e=\operatorname{Pr}=1, N t=0.2$, $\gamma_{1}=5, \gamma_{2}=10, M=0.5$ and $\lambda=-1,1$. 


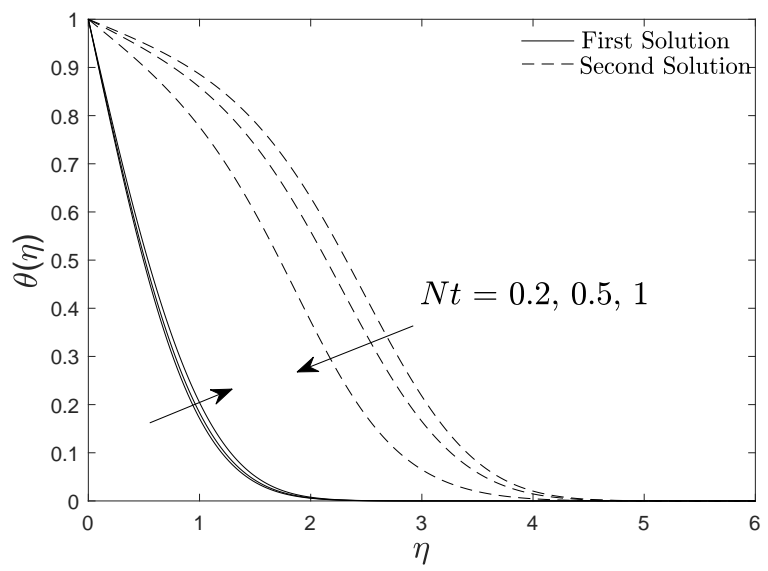

Figure 9. Nanofluid temperature in limiting range of $N t$ when $L e=\operatorname{Pr}=1, N b=0.2, \gamma_{1}=5, \gamma_{2}=10$, $M=0.5$ and $\lambda=-1,1$.

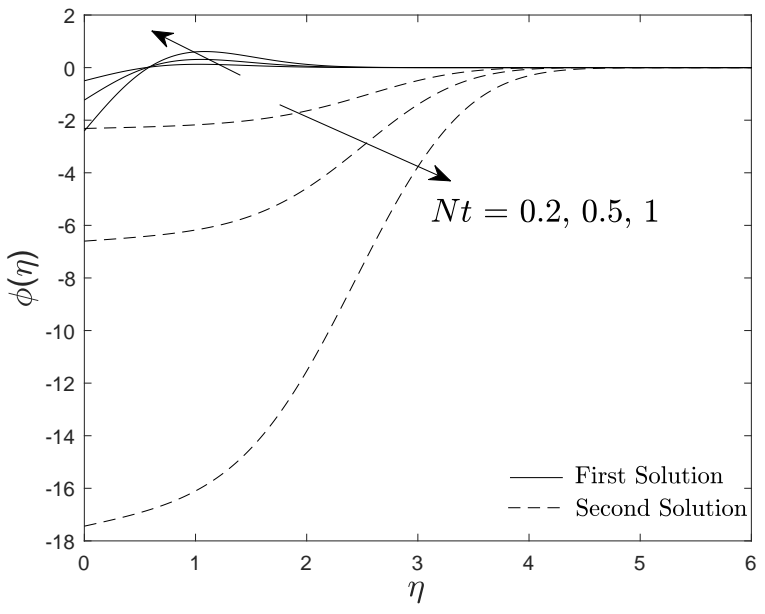

Figure 10. Nanoparticles' volume fraction profile in a limiting range of $N t$ when $L e=\operatorname{Pr}=1, N b=0.2$, $\gamma_{1}=5, \gamma_{2}=10, M=0.5$ and $\lambda=-1,1$.

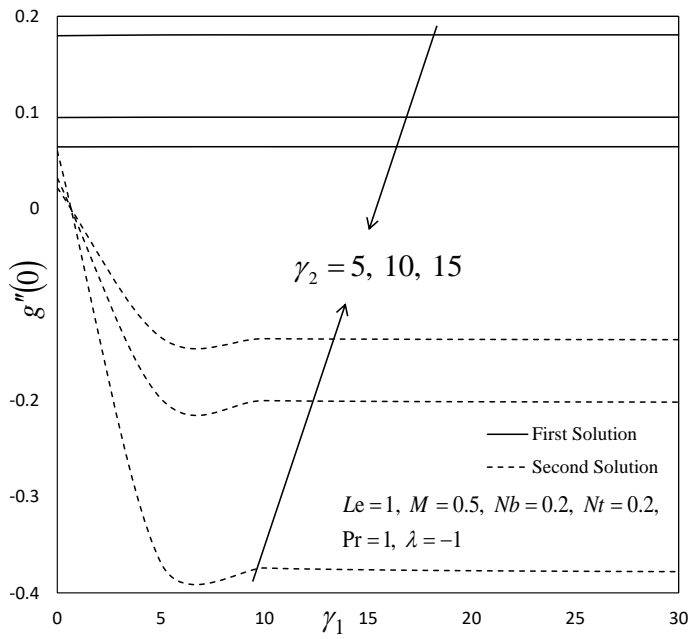

Figure 11. Variations of $g^{\prime \prime}(0)$ towards $\gamma_{1}$ for selected values of $\gamma_{2}$. 


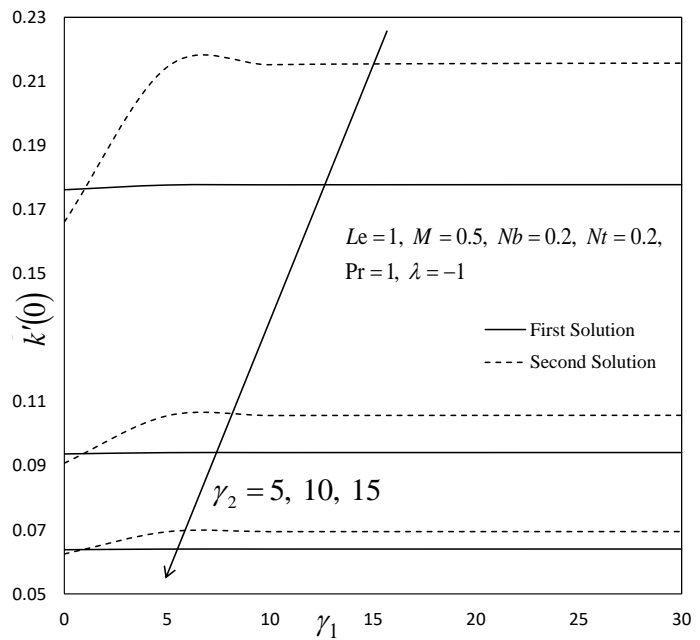

Figure 12. Variations of $k^{\prime}(0)$ towards $\gamma_{1}$ for selected values of $\gamma_{2}$.

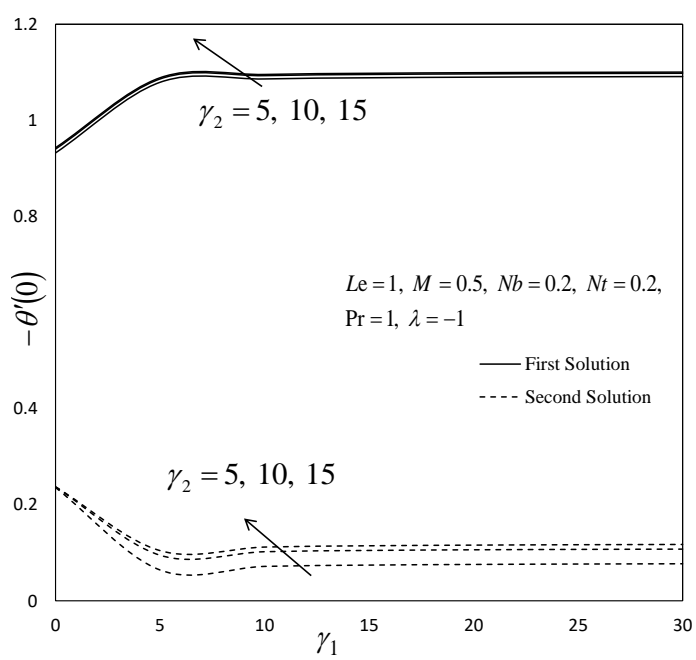

Figure 13. Variations of $-\theta^{\prime}(0)$ towards $\gamma_{1}$ for selected values of $\gamma_{2}$.

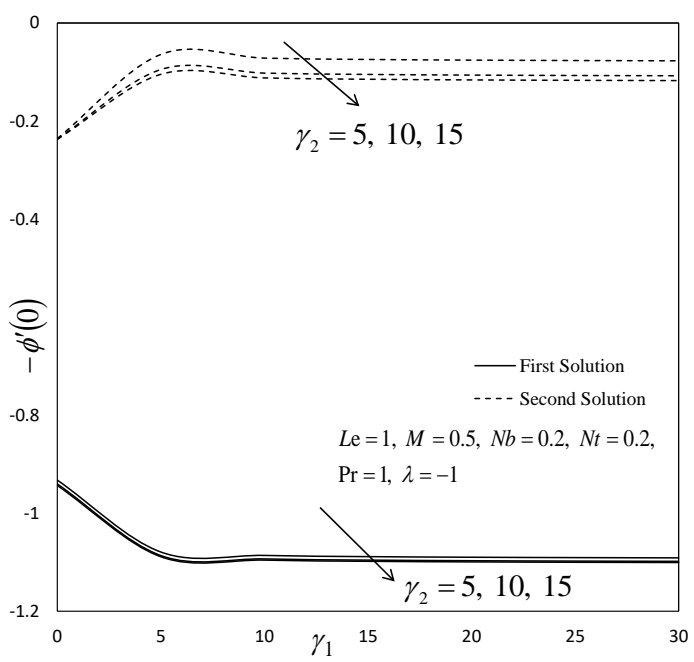

Figure 14. Variations of $-\phi^{\prime}(0)$ towards $\gamma_{1}$ for selected values of $\gamma_{2}$. 


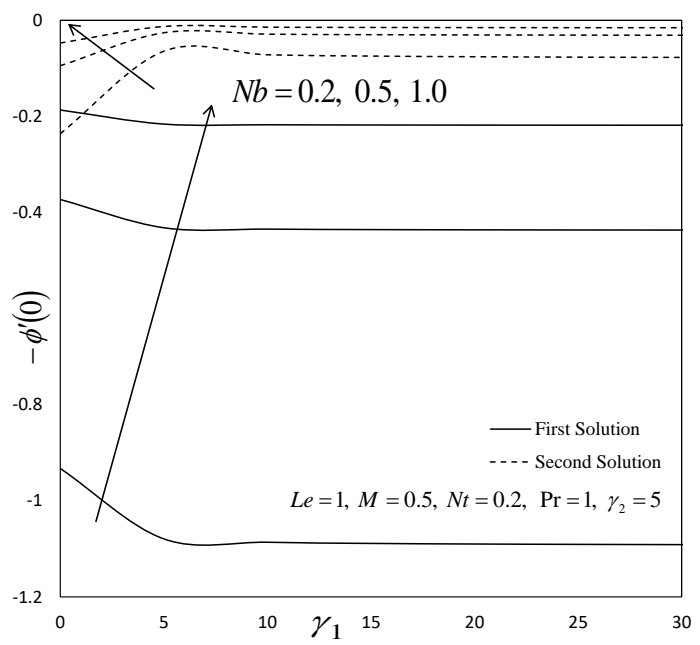

Figure 15. Variations of $-\phi^{\prime}(0)$ towards $\gamma_{1}$ for selected values of $N b$.

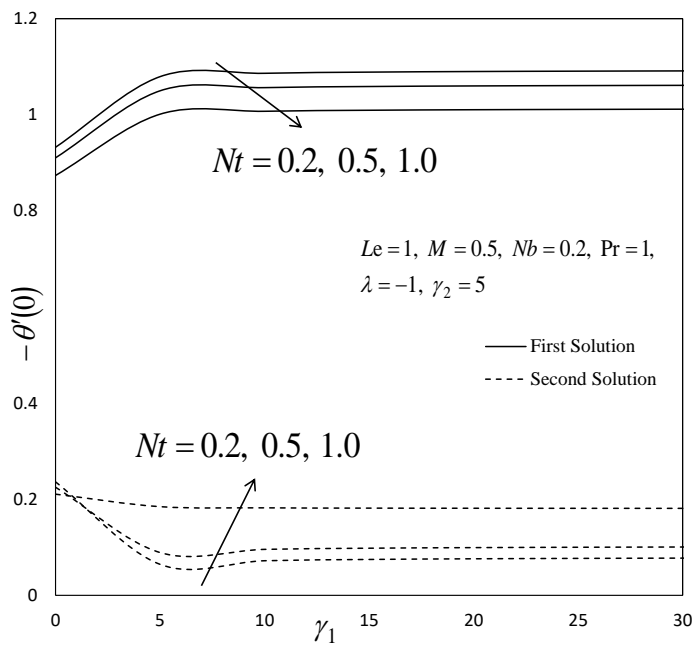

Figure 16. Variations of $-\theta^{\prime}(0)$ towards $\gamma_{1}$ for selected values of $N t$.

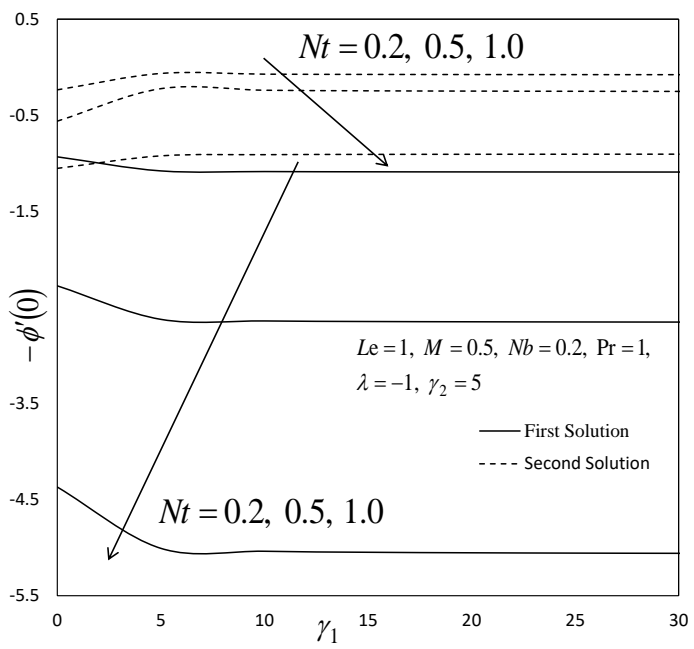

Figure 17. Variations of $-\phi^{\prime}(0)$ towards $\gamma_{1}$ for selected values of $N t$. 
Table 2. $\sigma_{1}$ for diverse $\gamma_{1}$ when $\gamma_{2}=5, L e=1, N b=N t=0.2, M=0.5, \operatorname{Pr}=1$ and $\lambda=-1$.

\begin{tabular}{ccc}
\hline$\gamma_{\mathbf{1}}$ & $\begin{array}{c}\sigma_{\mathbf{1}} \\
\text { (First Solution) }\end{array}$ & $\begin{array}{c}\sigma_{\mathbf{1}} \\
\text { (Second Solution) }\end{array}$ \\
\hline 3 & 0.2051 & -0.7977 \\
5 & 0.3720 & -0.8347 \\
10 & 0.4375 & -0.8626 \\
13 & 0.4590 & -0.8692 \\
15 & 0.4690 & -0.8721 \\
\hline
\end{tabular}

\section{Conclusions}

A numerical investigation on three-dimensional MHD stagnation point flow due to a moving plate with the presence of anisotropic slip has been accomplished. Buongiorno's model of nanofluid is selected to integrate the thermophoresis and Brownian motion parameters. A set of transformations was used to reduce the governing model into a set of nonlinear differential equations. The similarity equations are then transformed into the bvp4c algorithm to perform the numerical computation. The numerical results are illustrated graphically on the specific physical parameters such as thermophoresis parameter $N t$, slip parameters $\gamma_{1}, \gamma_{2}$ and Brownian motion parameter $N b$ to study the flow, heat and mass transfer characteristics of the nanofluid. Non-unique solutions exist boundlessly for all positive values of related parameters in the present study. The implementation of stability analysis using bvp4c code proves the reliability of the first solution. The thickness of boundary layer for the non-physical solution is larger compared to the physical solution. The rate of heat transfer is reduced with the augmentation of the anisotropic slip (difference of slip velocities), while the opposite result is obtained for the mass transfer rate. The rising values of $\mathrm{Nb}$ reduce the boundary layer thickness for nanoparticle concentration and increase the Sherwood number while an adverse trend is observed for the higher values of $N t$.

Author Contributions: Research design, N.S.K., N.M.A., R.N. and I.P.; Formulation and methodology, N.S.K. and N.M.A.; Result analysis, N.S.K.; Validation, N.M.A., R.N., E.H.H. and N.W.; Article preparation, N.S.K.; Review and editing, N.M.A., R.N., E.H.H., N.W. and I.P.

Funding: The authors would like to express their great appreciation to the Universiti Putra Malaysia through the Putra Grant (9570600). The main author also would like to acknowledge Universiti Teknikal Malaysia Melaka and Ministry of Education (Malaysia) for the financial support through a UTEM-SLAB scholarship. The work by Ioan Pop has been supported from the grant PN-III-P4-ID-PCE-2016-0036, UEFISCDI, Romania.

Acknowledgments: The authors appreciate the valuable feedback and recommendations by the reviewers.

Conflicts of Interest: The authors declare no conflict of interest. 


\section{Abbreviations}

The following abbreviations are used in this manuscript:

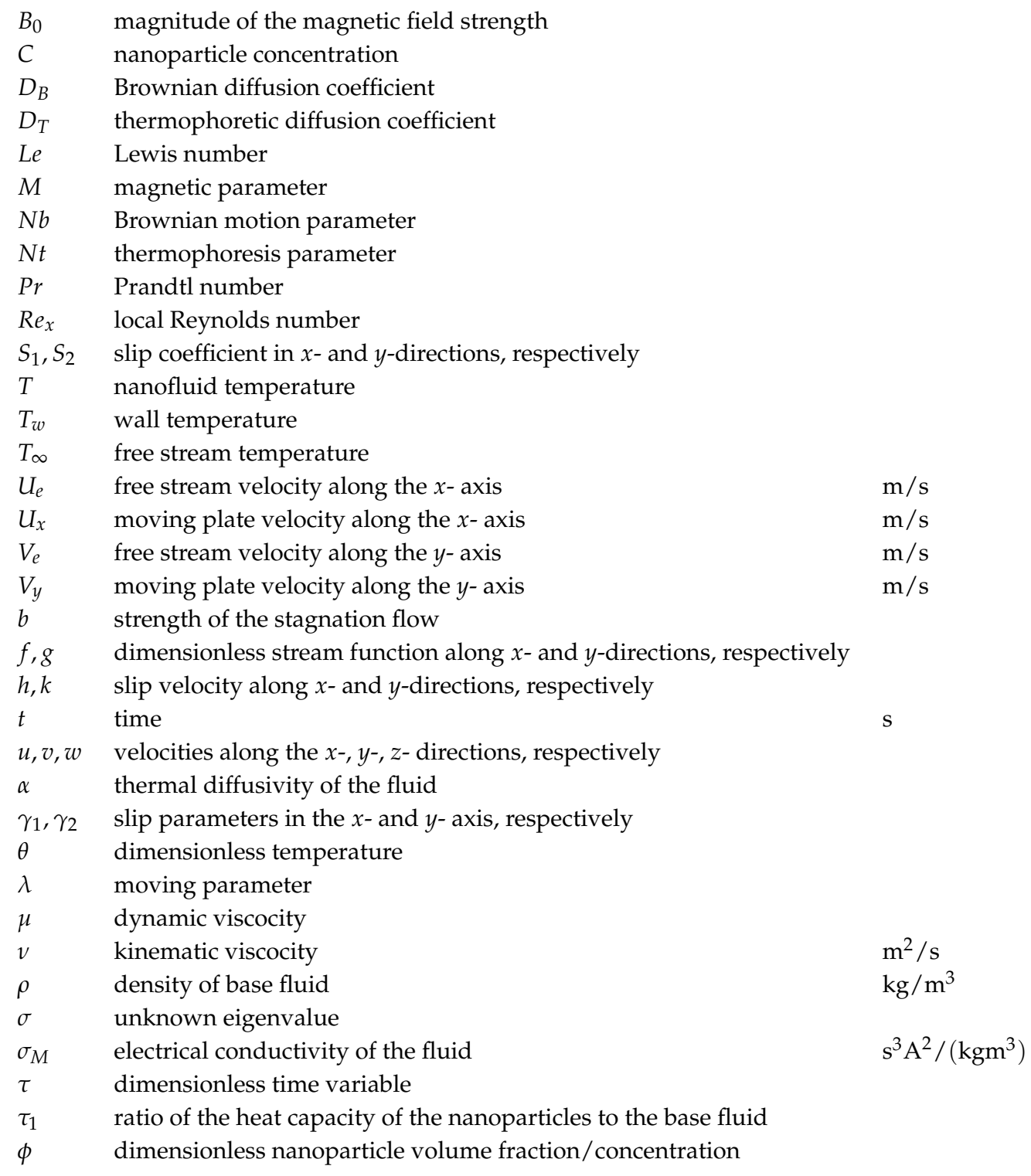

\section{References}

1. Haddad, Z.; Oztop, H.F.; Abu-Nada, E.; Mataoui, A. A review on natural convective heat transfer of nanofluids. Renew. Sust. Energy Rev. 2012, 16, 5363-5378. [CrossRef]

2. Mahian, O.; Kianifar, A.; Kalogirou, S.A.; Pop, I.; Wongwises, S. A review of the applications of nanofluids in solar energy. Int. J. Heat Mass Trans. 2013, 57, 582-594. [CrossRef]

3. Mohyud-Din, S.T.; Khan, U.; Ahmed, N.; Hassan, S.M. Magnetohydrodynamic flow and heat transfer of nanofluids in stretchable convergent/divergent channels. Appl. Sci. 2015, 5, 1639-1664. [CrossRef]

4. Sidik, N.A.; Yazid, M.N.; Mamat, R. A review on the application of nanofluids in vehicle engine cooling system. Int. Commun. Heat Mass. 2015, 68, 85-90. [CrossRef]

5. Sarkar, J.; Ghosh, P.; Adil, A. A review on hybrid nanofluids: recent research, development and applications. Renew. Sustain. Energy Rev. 2015, 43, 164-177. [CrossRef]

6. Ebrahimnia-Bajestan, E.; Moghadam, M.C.; Niazmand, H.; Daungthongsuk, W.; Wongwises, S. Experimental and numerical investigation of nanofluids heat transfer characteristics for application in solar heat exchangers. Int. J. Heat Mass Trans. 2016, 92, 1041-1052. [CrossRef] 
7. Al-Waeli, A.H.; Sopian, K.; Kazem, H.A.; Chaichan, M.T. Photovoltaic solar thermal (PV/T) collectors past, present and future: A review. Int. J. Appl. Eng. Res. 2016, 11, 10757-10765.

8. Fetecau, C.; Vieru, D.; Azhar, W.A. Natural convection flow of fractional nanofluids over an isothermal vertical plate with thermal radiation. Appl. Sci. 2017, 7, 247. [CrossRef]

9. Kasaeian, A.; Daneshazarian, R.; Mahian, O.; Kolsi, L.; Chamkha, A.J.; Wongwises, S.; Pop, I. Nanofluid flow and heat transfer in porous media: a review of the latest developments. Int. J. Heat Mass Trans. 2017, 107, 778-791. [CrossRef]

10. Khan, N.S.; Gul, T.; Islam, S.; Khan, I.; Alqahtani, A.M.; Alshomrani, A.S. Magnetohydrodynamic nanoliquid thin film sprayed on a stretching cylinder with heat transfer. Appl. Sci. 2017, 7, 271. [CrossRef]

11. Alobaid, M.; Hughes, B.; Heyes, A.; O'Connor, D. Determining the effect of inlet flow conditions on the thermal efficiency of a flat plate solar collector. Fluids 2018, 3, 67. [CrossRef]

12. Maleki, H.; Safaei, M.R.; Togun, H.; Dahari, M. Heat transfer and fluid flow of pseudo-plastic nanofluid over a moving permeable plate with viscous dissipation and heat absorption/generation. J. Therm. Anal. Calorim. 2018, 1 -12. [CrossRef]

13. Maleki, H.; Safaei, M.R.; Alrashed, A.A.; Kasaeian, A. Flow and heat transfer in non-Newtonian nanofluids over porous surfaces. J. Therm. Anal. Calorim. 2018, 1-12. [CrossRef]

14. Choi, S.U.; Zhang, Z.G.; Yu, W.; Lockwood, F.E.; Grulke, E.A. Anomalous thermal conductivity enhancement in nanotube suspensions. Appl. Phys. Lett. 2001, 79, 2252-2254. [CrossRef]

15. Buongiorno, J. Convective transport in nanofluids. J. Heat Trans. 2006, 128, 240-250. [CrossRef]

16. Nield, D.A.; Kuznetsov, A.V. The Cheng-Minkowycz problem for natural convective boundary-layer flow in a porous medium saturated by a nanofluid. Int. J. Heat Mass Trans. 2009, 52, 5792-5795. [CrossRef]

17. Buongiorno, J.; Venerus, D.C.; Prabhat, N.; McKrell, T.; Townsend, J.; Christianson, R.; Tolmachev, Y.V.; Keblinski, P.; Hu, L.W.; Alvarado, J.L.; et al. A benchmark study on the thermal conductivity of nanofluids. J. Appl. Phys. 2009, 106, 094312. [CrossRef]

18. Kuznetsov, A.V.; Nield, D.A. The Cheng-Minkowycz problem for natural convective boundary layer flow in a porous medium saturated by a nanofluid: A revised model. Int. J. Heat Mass Trans. 2013, 65, 682-685. [CrossRef]

19. Muhammad, T.; Alsaedi, A.; Shehzad, S.A.; Hayat, T. A revised model for Darcy-Forchheimer flow of Maxwell nanofluid subject to convective boundary condition. Chi. J. Phys. 2017, 55, 963-976. [CrossRef]

20. Rehman, S.U.; Haq, R.U.; Khan, Z.H.; Lee, C. Entropy generation analysis for non-Newtonian nanofluid with zero normal flux of nanoparticles at the stretching surface. J. Taiwan Inst. Chem. Eng. 2016, 63, 226-235. [CrossRef]

21. Rahman, M.M.; Al-Rashdi, M.H.; Pop, I. Convective boundary layer flow and heat transfer in a nanofluid in the presence of second order slip, constant heat flux and zero nanoparticles flux. Nucl. Eng. Des. 2016, 297, 95-103. [CrossRef]

22. Uddin, I.; Khan, M.A.; Ullah, S.; Islam, S.; Israr, M.; Hussain, F. Characteristics of buoyancy force on stagnation point flow with magneto-nanoparticles and zero mass flux condition. Results Phys. 2018, 8, 160-168. [CrossRef]

23. Ur Rahman, M.; Khan, M.; Manzur, M. Boundary layer flow and heat transfer of a modified second grade nanofluid with new mass flux condition. Results Phys. 2018, 10, 594-600. [CrossRef]

24. Jusoh, R.; Nazar, R.; Pop, I. Three-dimensional flow of a nanofluid over a permeable stretching/shrinking surface with velocity slip: A revised model. Phus. Fluids 2018, 30, 033604. [CrossRef]

25. Roşca, N.C.; Pop, I. Unsteady boundary layer flow of a nanofluid past a moving surface in an external uniform free stream using Buongiorno's model. Comput. Fluids 2014, 95, 49-55. [CrossRef]

26. Mabood, F.; Khan, W.A.; Ismail, A.M. MHD boundary layer flow and heat transfer of nanofluids over a nonlinear stretching sheet: A numerical study. J. Magn. Magn. Mater. 2015, 374, 569-576. [CrossRef]

27. Sheikholeslami, M.; Ganji, D.D.; Javed, M.Y.; Ellahi, R. Effect of thermal radiation on magnetohydrodynamics nanofluid flow and heat transfer by means of two phase model. J. Magn. Magn. Mater. 2015, 374, 36-43. [CrossRef]

28. Bakar, N.A.; Bachok, N.; Arifin, N.M. Moving plate in a nanofluid using Buongiorno model and thermophysical properties of nanoliquids. JP J. Heat Mass Trans. 2017, 14, 119. [CrossRef]

29. Bakar, N.A.; Bachok, N.; Arifin, N.M. Rotating flow over a shrinking sheet in nanofluid using Buongiorno model and thermophysical properties of nanoliquids. J. of Nanofluids 2017, 6, 1215-1226. [CrossRef] 
30. Bakar, N.A.; Bachok, N.; Arifin, N.M. Stability analysis on the flow and heat transfer of nanofluid past a stretching/shrinking cylinder with suction effect. Results Phys. 2018, 9, 1335-1344. [CrossRef]

31. Othman, N.A.; Yacob, N.A.; Bachok, N.; Ishak, A.; Pop, I. Mixed convection boundary-layer stagnation point flow past a vertical stretching/shrinking surface in a nanofluid. Appl. Therm. Eng. 2017, 115, 1412-1417. [CrossRef]

32. Rashidi, M.M.; Laraqi, N.; Parsa, A.B. Analytical modeling of heat convection in magnetized micropolar fluid by using modified differential transform method. Heat Trans. Asian Res. 2011, 40, 187-204. [CrossRef]

33. Rashidi, M.M.; Abelman, S.; Mehr, N.F. Entropy generation in steady MHD flow due to a rotating porous disk in a nanofluid. Int. J. Heat Mass Trans. 2013, 62, 515-525. [CrossRef]

34. Sheikholeslami, M.; Gorji-Bandpy, M.; Ganji, D.D. MHD free convection in an eccentric semi-annulus filled with nanofluid. J. Taiwan Inst. Chem. Eng. 2014, 45, 1204-1216. [CrossRef]

35. Hayat, T.; Imtiaz, M.; Alsaedi, A.; Kutbi, M.A. MHD three-dimensional flow of nanofluid with velocity slip and nonlinear thermal radiation. J. Magn. Magn. Mater. 2015, 396, 31-37. [CrossRef]

36. Kandasamy, R.; Jeyabalan, C.; Prabhu, K.S. Nanoparticle volume fraction with heat and mass transfer on MHD mixed convection flow in a nanofluid in the presence of thermo-diffusion under convective boundary condition. Appl. Nanosci. 2016, 6, 287-300. [CrossRef]

37. Bhatti, M.M.; Abbas, T.; Rashidi, M.M. Numerical study of entropy generation with nonlinear thermal radiation on magnetohydrodynamics non-Newtonian nanofluid through a porous shrinking sheet. J. Magn. 2016, 21, 468-475. [CrossRef]

38. Bhatti, M.M.; Abbas, M.A.; Rashidi, M.M. Combine effects of Magnetohydrodynamics (MHD) and partial slip on peristaltic Blood flow of Ree-Eyring fluid with wall properties. Eng. Sci. Technol. Int. J. 2016, 19, 1497-1502. [CrossRef]

39. Makulati, N.; Kasaeipoor, A.; Rashidi, M.M. Numerical study of natural convection of a water-alumina nanofluid in inclined C-shaped enclosures under the effect of magnetic field. Adv. Powder Technol. 2016, 27, 661-672. [CrossRef]

40. Hussain, S.M.; Jain, J.; Seth, G.S.; Rashidi, M.M. Free convective heat transfer with hall effects, heat absorption and chemical reaction over an accelerated moving plate in a rotating system. J. Magn. Magn. Mater. 2017, 422, 112-123. [CrossRef]

41. Hiemenz, K. Die Grenzschicht an einem in den gleichformigen Flussigkeitsstrom eingetauchten geraden Kreiszylinder. Dinglers Polytech. J. 1911, 326, 321-324.

42. Homann, F. Der Einfluss grosser Zähigkeit bei der Strömung um den Zylinder und um die Kugel. ZAMM J. Appl. Math. Mech./Z. Angew. Math. Mech. 1936, 16, 153-164. [CrossRef]

43. Howarth, L. The boundary layer in three dimensional flow-Part II. The flow near a stagnation point. Lond. Edinb. Dublin Philos. Mag. J. Sci. 1951, 42, 1433-1440. [CrossRef]

44. Wang, C.Y. Stagnation flow on a plate with anisotropic slip. Eur. J. Mech. B/Fluids. 2013, 38, 73-77. [CrossRef]

45. Wang, C.Y. Stagnation flows with slip: Exact solutions of the Navier-Stokes equations. Z. Angew. Math. Phys. (ZAMP) 2003, 54, 184-189. [CrossRef]

46. Wang, C.Y. Stagnation slip flow and heat transfer on a moving plate. Chem. Eng. Sci. 2006, 61, 7668-7672. [CrossRef]

47. Hussain, S.; Aziz, A.; Aziz, T.; Khalique, C.M. Slip flow and heat transfer of nanofluids over a porous plate embedded in a porous medium with temperature dependent viscosity and thermal conductivity. Appl. Sci. 2016, 6, 376. [CrossRef]

48. Khan, M; Hashim; Hafeez, A. A review on slip-flow and heat transfer performance of nanofluids from a permeable shrinking surface with thermal radiation: Dual solutions. Chem. Eng. Sci. 2017, 173, 1-11. [CrossRef]

49. Belyaev, A.V.; Vinogradova, O.I. Electro-osmosis on anisotropic superhydrophobic surfaces. Phys. Rev. Lett. 2011, 107, 098301. [CrossRef]

50. Jung, T.; Choi, H.; Kim, J. Effects of the air layer of an idealized superhydrophobic surface on the slip length and skin-friction drag. J. Fluid Mech. 2016, 790. [CrossRef]

51. Pearson, J.T.; Bilodeau, D.; Maynes, D. Two-pronged jet formation caused by droplet impact on anisotropic superhydrophobic surfaces. J. Fluids Eng. 2016, 138, 074501. [CrossRef]

52. Schäffel, D.; Koynov, K.; Vollmer, D.; Butt, H.J.; Schönecker, C. Local flow field and slip length of superhydrophobic surfaces. Phys. Rev. Lett. 2016, 116, 134501. [CrossRef] [PubMed] 
53. Fan, B.; Bandaru, P.R. Anisotropy in the hydrophobic and oleophilic characteristics of patterned surfaces. Appl. Phys. Lett. 2017, 111, 261603. [CrossRef]

54. Alinovi, E.; Bottaro, A. Apparent slip and drag reduction for the flow over superhydrophobic and lubricant-impregnated surfaces. Phys. Rev. Fluids 2018, 3, 124002. [CrossRef]

55. Lu, J.; Jang, H.K.; Lee, S.B.; Hwang, W.R. Characterization on the anisotropic slip for flows over unidirectional fibrous porous media for advanced composites manufacturing. Compos. Part A Appl. Sci. Manuf. 2017, 100, 9-19. [CrossRef]

56. Pasquier, S.; Quintard, M.; Davit, Y. Modeling flow in porous media with rough surfaces: Effective slip boundary conditions and application to structured packings. Chem. Eng. Sci. 2017, 165, 131-146. [CrossRef]

57. Rashad, A.M. Unsteady nanofluid flow over an inclined stretching surface with convective boundary condition and anisotropic slip impact. Int. J. Heat Technol. 2017, 35, 82-90. [CrossRef]

58. Hafidzuddin, E.H.; Nazar, R.; Arifin, N.M.; Pop, I. Effects of anisotropic slip on three-dimensional stagnation-point flow past a permeable moving surface. Eur. J. Mech. B/Fluids. 2017, 65, 515-521. [CrossRef]

59. Raees, A.; Raees-ul-Haq, M.; Xu, H.; Sun, Q. Three-dimensional stagnation flow of a nanofluid containing both nanoparticles and microorganisms on a moving surface with anisotropic slip. Appl. Math. Model. 2016, 40, 4136-4150. [CrossRef]

60. Uddin, M.J.; Khan, W.A.; Ismail, A.M.; Bég, O.A. Computational study of three-dimensional stagnation point nanofluid bioconvection flow on a moving surface with anisotropic slip and thermal jump effect. J. Heat Trans. 2016, 138, 104502. [CrossRef]

61. Al-Balushi, L.M.; Rahman, M.M.; Pop, I. Three-dimensional axisymmetric stagnation-point flow and heat transfer in a nanofluid with anisotropic slip over a striated surface in the presence of various thermal conditions and nanoparticle volume fractions. Therm. Sci. Eng. Prog. 2017, 2, 26-42. [CrossRef]

62. Sadiq, M.A. MHD Stagnation point flow of nanofluid on a plate with anisotropic slip. Symmetry 2019, 11, 132. [CrossRef]

63. Merkin, J.H. On dual solutions occurring in mixed convection in a porous medium. J. Eng. Math. 1986, 20, 171-179. [CrossRef]

64. Weidman, P.D.; Kubitschek, D.G.; Davis, A.M. The effect of transpiration on self-similar boundary layer flow over moving surfaces. Int. J. Eng. Sci. 2006, 44, 730-737. [CrossRef]

65. Harris, S.D.; Ingham, D.B.; Pop, I. Mixed convection boundary-layer flow near the stagnation point on a vertical surface in a porous medium: Brinkman model with slip. Trans. Porous Med. 2009, 77, 267-285. [CrossRef]

66. Roşca, A.V.; Pop, I. Flow and heat transfer over a vertical permeable stretching/shrinking sheet with a second order slip. Int. J. Heat Mass Trans. 2013, 60, 355-364. [CrossRef]

67. Anuar, N.; Bachok, N; Pop, I. A stability analysis of solutions in boundary layer flow and heat transfer of carbon nanotubes over a moving plate with slip effect. Energies 2018, 11, 3243. [CrossRef]

68. Salleh, S.N.A.; Bachok, N.; Arifin, N.M.; Ali, F.M.; Pop, I. Stability analysis of mixed convection flow towards a moving thin needle in nanofluid. Appl. Sci. 2018, 8, 842. [CrossRef]

69. Najib, N.; Bachok, N.; Arifin, N.M.; Ali, F.M. Stability analysis of stagnation-point flow in a nanofluid over a stretching/shrinking sheet with second-order slip, soret and dufour effects: A revised model. Appl. Sci. 2018, 8, 642. [CrossRef]

70. Abu Bakar, S.; Arifin, N.M.; Md Ali, F.; Bachok, N.; Nazar, R.; Pop, I. A stability analysis on mixed convection boundary layer flow along a permeable vertical cylinder in a porous medium filled with a nanofluid and thermal radiation. Appl. Sci. 2018, 8, 483. [CrossRef]

71. Dzulkifli, N.; Bachok, N.; Yacob, N.; Md Arifin, N.; Rosali, H. Unsteady stagnation-point flow and heat transfer over a permeable exponential stretching/shrinking sheet in nanofluid with slip velocity effect: A stability analysis. Appl. Sci. 2018, 8, 2172. [CrossRef]

72. Jamaludin, A.; Nazar, R.; Pop, I. Three-dimensional magnetohydrodynamic mixed convection flow of nanofluids over a nonlinearly permeable stretching/shrinking sheet with velocity and thermal slip. Appl. Sci. 2018, 8, 1128. [CrossRef]

73. Yahaya, R.; Md Arifin, N.; Mohamed Isa, S. Stability analysis on magnetohydrodynamic flow of casson fluid over a shrinking sheet with homogeneous-heterogeneous reactions. Entropy 2018, 20, 652. [CrossRef] 
74. Jusoh, R.; Nazar, R.; Pop, I. Flow and heat transfer of magnetohydrodynamic three-dimensional Maxwell nanofluid over a permeable stretching/shrinking surface with convective boundary conditions. Int. J. Mech. Sci. 2017, 124, 166-173. [CrossRef]

75. Weidman, P.D.; Sprague, M.A. Flows induced by a plate moving normal to stagnation-point flow. Acta Mech. 2011, 219, 219-229. [CrossRef]

76. Jamaludin, A.; Nazar, R.; Pop, I. Three-dimensional mixed convection stagnation-point flow over a permeable vertical stretching/shrinking surface with a velocity slip. Chin. J. Phys. 2017, 55, 1865-1882. [CrossRef]

77. Rahman, M.M. Effects of second-order slip and magnetic field on mixed convection stagnation-point flow of a Maxwellian fluid: Multiple solutions. J. Heat Tran. 2016, 138, 122503. [CrossRef]

78. Borrelli, A.; Giantesio, G.; Patria, M.C.; Roşca, N.C.; Roşca, A.V.; Pop, I. Buoyancy effects on the 3D MHD stagnation-point flow of a Newtonian fluid. Commun. Nonlinear Sci. Numer. Simul. 2017, 43, 1-3. [CrossRef]

(C) 2019 by the authors. Licensee MDPI, Basel, Switzerland. This article is an open access article distributed under the terms and conditions of the Creative Commons Attribution (CC BY) license (http://creativecommons.org/licenses/by/4.0/). 